\title{
Parameter Identification of a Synchronous Reluctance Motor by using a Synchronous PI Current Regulator at a Standstill
}

\author{
Seon-Hwan Hwang*, Jang-Mok Kim ${ }^{\dagger}$, Huynh Van Khang**, and Jin-Woo Ahn*** \\ ${ }^{\dagger *}$ School of Electrical Eng., Pusan National University, Busan, Korea \\ ** Dept. of Electrical Eng., Aalto University, Finland \\ *** School of Electrical and Mechatronics Eng., Kyungsung University, Busan, Korea
}

\begin{abstract}
This paper proposes an estimation algorithm for the electrical parameters of synchronous reluctance motors (SynRMs) by using a synchronous PI current regulator at standstill. In reality, the electrical parameters are only measured or estimated in limited conditions without fully considering the effects of the switching devices, connecting wires, and magnetic saturation. As a result, the acquired electrical parameters are different from the real parameters of the motor drive system. In this paper, the effects of switching devices, connecting wires, and the magnetic saturation are considered by simultaneously using the short pulse and closed loop equations of resistance and synchronous inductances. Therefore, the proposed algorithm can be easily and safely implemented with a reduced measuring time. In addition, it does not need any external or additional measurement equipment, information on the motor's dimensions, and material characteristics as in the case of FEM. Several experimental results verify the effectiveness of the proposed algorithm.
\end{abstract}

Key Words: Closed loop equations, Electrical parameter estimation, Short pulse, Synchronous PI current regulator, Synchronous reluctance motor

\section{INTRODUCTION}

Recently, synchronous reluctance motors (SynRMs) have received a lot of attention because of their high output power, low cost, and endurance in various industry applications. The saliency rotor has no magnets or windings, so it is mechanically robust for high speed operation and it is suitable for sensorless control [1]-[4]. The phase resistance and synchronous inductances are the basic parameters describing SynRM behavior. The researchers in [5] showed that the electrical angle of a current vector with respect to the high permeance axis ( $d$-axis) is a function of the ratio of the $d$-and $q$-axis inductances for some control methods. The performance of the drive system depends on the PI gains of the synchronous PI current regulator and they are calculated from the electrical parameters [6]. Therefore, an exact measurement of the synchronous inductances is very important to the performance of the motor drive system.

For SynRMs, there is a nonlinear relationship between the stator inductances and the currents due to magnetic saturation in the $d$ - and $q$-axes, respectively. This causes some problems

\footnotetext{
Manuscript received Feb. 23, 2010; revised Jul. 14, 2010

† Corresponding Author: jmok@pusan.ac.kr

Tel: +82-51-510-2366, Fax: +82-51-513-0212, Pusan Nat'l Univ.

* School of Electrical Eng., Pusan Nat'l Univ., Korea

** Dept. of Electrical Eng., Aalto Univ., Finland

*** School of Electrical and Mechatronics Eng., Kyungsung Univ., Korea
}

for accurate control of the SynRM [7]-[9]. It is not easy to measure the exact inductance parameters of a SynRM while considering the saturation effect. Several methods that measure or calculate the electrical parameters of a motor have already been proposed in [10], [11]. These methods simply measure the phase inductances but they need an external circuit. Moreover, they need to know the position information [10] or have to calculate a complex flux polynomial to obtain the synchronous inductances [11]. The researchers in [12] measured the SynRM synchronous inductances considering the iron loss from a single phase test. The phase current, voltage, active power, position information, and dc stator resistance are necessary for the synchronous inductance identification. In recent years, the Finite Element Method (FEM) has been applied to simulate the parameters under ideal conditions [13]. However, FEM requires the motor dimensions and the material characteristics to calculate the electrical parameters. To consider the parameters in a real situation, the inductances were calculated recursively from the measured voltages and currents, their previous values and the constant stator resistance [14]. The very important role of electrical parameters for sensorless control was considered in [15]. By using the recursive least-square method, the authors directly identified the electrical parameters in the sensorless control of a SynRM. This method estimated the electrical parameters by using the 


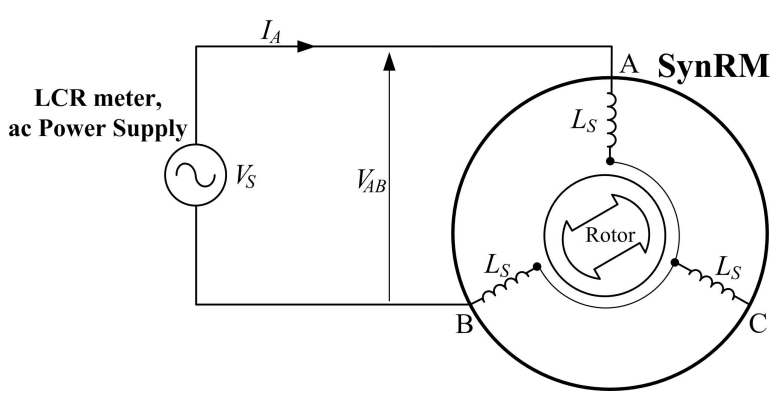

Fig. 1. Measurement diagram of stator inductances using an LCR meter.

measured voltages and currents, the identified matrices and their previous values. These conventional methods, in brief, are very complex to implement or can only be used under constrained conditions.

A synchronous PI current regulator is widely used for ac machine drives due to its capability in regulating ac signals over a wide frequency range [16], [17]. Electrical parameters are used to calculate the PI gains of a synchronous PI current regulator. As a result, the drive performance can be guaranteed by using the exactly measured electrical parameters.

This paper proposes a new method that uses a synchronous PI current regulator to measure the exact electrical parameters of the SynRM at a standstill, taking into full consideration the effects of both the switching devices and the connecting wire resistance. The influences of the parameters on the drive performance are also verified through several experimental results.

\section{Two Conventional Methods}

\section{A. Using an LCR meter}

In general, the three phase inductances of a SynRM are given by [18]:

$$
\begin{aligned}
& L(\theta)=\left[\begin{array}{ccc}
L_{s} & L_{m s} & L_{m s} \\
L_{m s} & L_{s} & L_{m s} \\
L_{m s} & L_{m s} & L_{s}
\end{array}\right] \\
& +L_{m}\left[\begin{array}{ccc}
\cos (2 N \theta) & \cos \left(2 N \theta-\frac{2 \pi}{3}\right) & \cos \left(2 N \theta+\frac{2 \pi}{3}\right) \\
\cos \left(2 N \theta-\frac{2 \pi}{3}\right) & \cos \left(2 N \theta+\frac{2 \pi}{3}\right) & \cos (2 N \theta) \\
\cos \left(2 N \theta+\frac{2 \pi}{3}\right) & \cos (2 N \theta) & \cos \left(2 N \theta-\frac{2 \pi}{3}\right)
\end{array}\right]
\end{aligned}
$$

where, $L_{s}$ is the average stator self-inductance, $L_{m s}$ is the stator mutual inductance, $L_{m}$ is one of the stator inductances due to the rotor saliency, and $N$ is the number of pole pairs.

In a synchronous reference frame, the $d$ - and $q$ - axis synchronous inductances of the SynRM stator can be acquired by using the Park transformation.

$$
\begin{aligned}
& L_{d}=L_{s}-L_{m s}+1.5 L_{m} \\
& L_{q}=L_{s}-L_{m s}-1.5 L_{m} .
\end{aligned}
$$

Fig. 1 shows a measurement diagram of the two phase inductances using an LCR meter.

The inductance expression between the two phases, $L_{A B}$ can be expressed as:

$$
L_{A B}=2 L_{s}-2 L_{m s}-3 L_{m} \cos \left(2 N \theta-\frac{2 \pi}{3}\right) .
$$

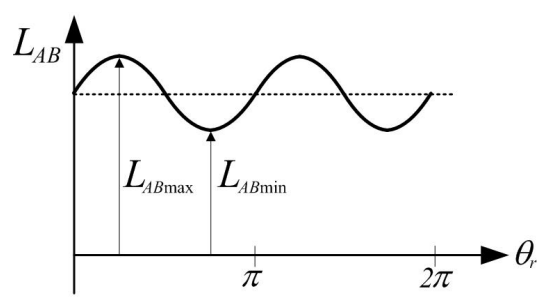

Fig. 2. Inductance as a function of rotor position.

Applying (4) to (2) and (3), the $d$ - and $q$-axis inductances of the SynRM can be derived in (5) and (6), respectively.

$$
\begin{aligned}
L_{d} & =\frac{L_{A B \max }}{2} \\
L_{q} & =\frac{L_{A B \min }}{2} .
\end{aligned}
$$

The LCR meter can measure the line to line resistances at the actual rotor terminals. The phase resistance $R_{s}$ can be easily obtained by:

$$
R_{s}=\frac{R_{A B, a v g}}{2}
$$

where, $R_{A B, \text { avg }}$ is the average resistance value between the A- and B-phases.

$L_{A B \max }$ and $L_{A B \min }$ are the maximum and minimum inductances between the A- and B- terminals according to the rotor position as shown in Fig. 2.

\section{B. Using the ac voltage and current source}

The principle of measurement using the ac voltage and current (called the VI method in this paper) is similar to that of the LCR meter shown in Figs. 1 and 2. The power system supplies a sine voltage to the A- and B-terminals. The inductance between the two phases can be calculated as:

$$
L_{A B}=\frac{1}{\omega} \sqrt{\left(\frac{V}{I}\right)^{2}-4 R_{s}^{2}}
$$

where, $\omega$ is the frequency of the applied sine voltage, $I$ is the rms current that flows through the A-phase and the B-phase, $V$ is the voltage between the two phases, and $R_{s}$ is the measured phase resistance from the prior dc test.

In the VI method, the stator current and voltage can be measured by slowly rotating the rotor mechanically from 0 to $2 \pi$ in one direction. The change in the line to line inductances that occurs as the rotor is rotated is depicted in Fig. 2. The resultant synchronous inductances $L_{d}$ and $L_{q}$ can be calculated by using (5), (6), and (8).

This method has some disadvantages in obtaining the profile of the inductances. Firstly, it takes a lot of time to measure the inductances. Secondly, it requires additional equipment such as voltage/current meters, and an ac power supply. Thirdly, using dc resistance in an inductance equation (8) causes measurement errors in calculating the synchronous inductance due to the error of the constant dc resistance. Finally, in order to get a wide range of values of the inductances, measurements using a greater than nominal current $\left(I_{r m s}>I_{n o m}\right)$ could heat and damage the SynRM because of the long term exposure to high temperature. 


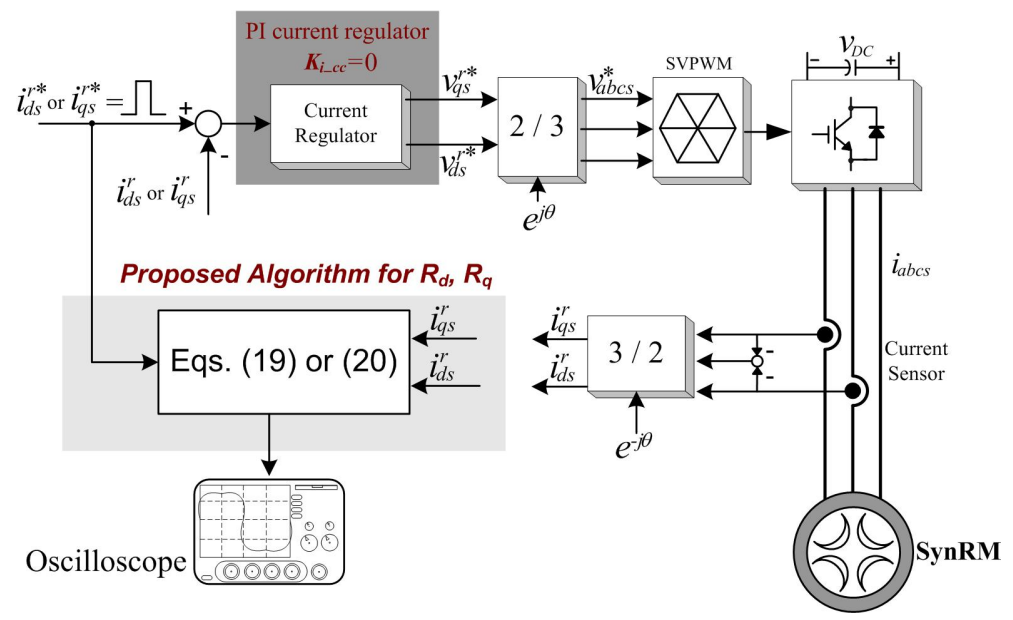

Fig. 3. Conceptual diagram for resistance measurement.

\section{Proposed Online Measurement Method}

The conventional methods can only measure the electrical parameters of the motor. In order to consider the effects of the switching devices as well as the connecting wires, the real inverter system must be analyzed and used to measure the electrical parameters.

\section{A. Relationship between current deviation and electrical pa- rameters}

The $d$ - and $q$-axis output voltages of a synchronous PI current regulator can be written at a standstill $\left(\omega_{e}=0\right)$ in the Laplace Transform Domain (LTD) as in (9) and (10).

$$
\begin{aligned}
V_{d}^{r^{*}}(s) & =\frac{1}{s}\left[I_{d}^{r^{*}}(s)-I_{d}^{r}(s)\right]\left[K_{i d_{-} c c}+s K_{p d_{-} c c}\right] \\
V_{q}^{r^{*}}(s) & =\frac{1}{s}\left[I_{q}^{r^{*}}(s)-I_{q}^{r}(s)\right]\left[K_{i q_{-} c c}+s K_{p q_{-} c c}\right]
\end{aligned}
$$

where, $K_{i d_{-} c c}=R_{d}^{*} \omega_{c c}, K_{i q_{-} c c}=R_{q}^{*} \omega_{c c}, K_{p d_{-} c c}=L_{d}^{*} \omega_{c c}$, and $K_{p q_{-} c c}=L_{q}^{*} \omega_{c c}$ are the PI gains of the synchronous PI current regulator. $R_{d}^{*} \& R_{q}^{*}$, and $L_{d}^{*} \& L_{q}^{*}$ are the known $d$ and $q$-axis resistances and inductances respectively, $\omega_{c c}$ is the current regulator's bandwidth, which is directly related to the sampling time of the synchronous PI current regulator and the switching frequency [6]. $V_{d}^{r^{*}}(s)$ and $V_{q}^{r^{*}}(s)$ are the outputs of the synchronous PI current regulator, while $I_{d}^{r^{*}}(s)$ and $I_{q}^{r^{*}}(s)$ are the $d$ - and $q$-axis reference currents calculated from the output of the speed controller. The terms, $I_{d}^{r}(s)$ and $I_{q}^{r}(s)$, are the real $d$ - and $q$-axis currents measured from the motor terminals.

The mathematical model of a SynRM is given by:

$$
\left\{\begin{array}{l}
v_{d}^{r}(t)=R_{s} i_{d}^{r}(t)+L_{d} \frac{d i_{d}^{r}(t)}{d t}-\omega_{e} L_{q} i_{q}^{r}(t) \\
v_{q}^{r}(t)=R_{s} i_{q}^{r}(t)+L_{q} \frac{d i_{q}^{r}(t)}{d t}+\omega_{e} L_{d} i_{d}^{r}(t)
\end{array}\right.
$$

where, $v_{d}^{r}(t)$ and $v_{q}^{r}(t)$ are the $d$ - and $q$ - axis terminal voltages in the synchronous reference frame.

The LTD equation of (11) at standstill can be derived as:

$$
\left\{\begin{array}{l}
V_{d}^{r}(s)=\left(R_{s}+s L_{d}\right) I_{d}^{r}(s) \\
V_{q}^{r}(s)=\left(R_{s}+s L_{q}\right) I_{q}^{r}(s)
\end{array} .\right.
$$

Fig. 3 shows a control block diagram of the SynRM drive system without a speed controller. The relationship between the reference voltages and the terminal voltages is as follows:

$$
\left\{\begin{array}{l}
V_{d}^{r^{*}}(s)=V_{d}^{r}(s)+\left[R_{d L}+R_{d s w}\right] I_{d}^{r}(s) \\
V_{q}^{r^{*}}(s)=V_{q}^{r}(s)+\left[R_{q L}+R_{q s w}\right] I_{q}^{r}(s)
\end{array}\right.
$$

where, $R_{d L}$ and $R_{q L}$ are the $d$ - and $q$ - axis connecting wire resistances. $R_{d s w}$ and $R_{q s w}$ represent the nonlinear effects of the switching devices.

From (12) and (13), the current deviation between the real and the reference currents can be derived as:

$$
\begin{aligned}
& I_{d}^{r^{*}}(s)-I_{d}^{r}(s)=\frac{s L_{d}+R_{d}}{K_{i d_{\_} c c}+s K_{p d_{-} c c}} s I_{d}^{r}(s) \\
& I_{q}^{r^{*}}(s)-I_{q}^{r}(s)=\frac{s L_{q}+R_{q}}{K_{i q_{-} c c}+s K_{p d_{-} c c}} s I_{q}^{r}(s)
\end{aligned}
$$

where, $R_{d}=R_{s}+R_{d L}+R_{d s w}$ and $R_{q}=R_{s}+R_{q L}+R_{q s w}$ are the real $d$ - and $q$-axis resistances, respectively.

\section{B. Measurement of resistances at a standstill}

In this section, a method of determining the resistance by using a synchronous PI current regulator is proposed by using the above analysis. If $K_{i d_{-} c c}$ is zero, the transfer function of the $d$-axis current is easily derived as in (16) from (14).

$$
\frac{I_{d}^{r}(s)}{I_{d}^{r *}(s)}=\frac{K_{p d_{-} c c}}{s L_{d}+R_{d}+K_{p d_{-} c c}} .
$$

When a step function of the $d$-axis current reference is applied, the transient state equation of the $d$-axis current can be derived as:

$$
i_{d}^{r}(t)=\frac{i_{d}^{r^{*}}(t) K_{p d \_c c}}{R_{d}+K_{p d \_c c}}\left(1-e^{\frac{R_{d}+K_{p d \_c c}}{L_{d}} t}\right) .
$$

Because $L_{d}<<R_{d}+K_{p d \_c c}$, the $d$-axis current at the steady state can be approximately obtained as:

$$
i_{d}^{r}(t)=\frac{K_{p d_{-} c c}}{R_{d}+K_{p d_{-} c c}} i_{d}^{r^{*}}(t) .
$$

From (18), the $d$-axis resistance is calculated like (19).

$$
R_{d}=\frac{i_{d}^{r^{*}}(t)}{i_{d}^{r}(t)} K_{p d \_c c}-K_{p d \_c c} .
$$




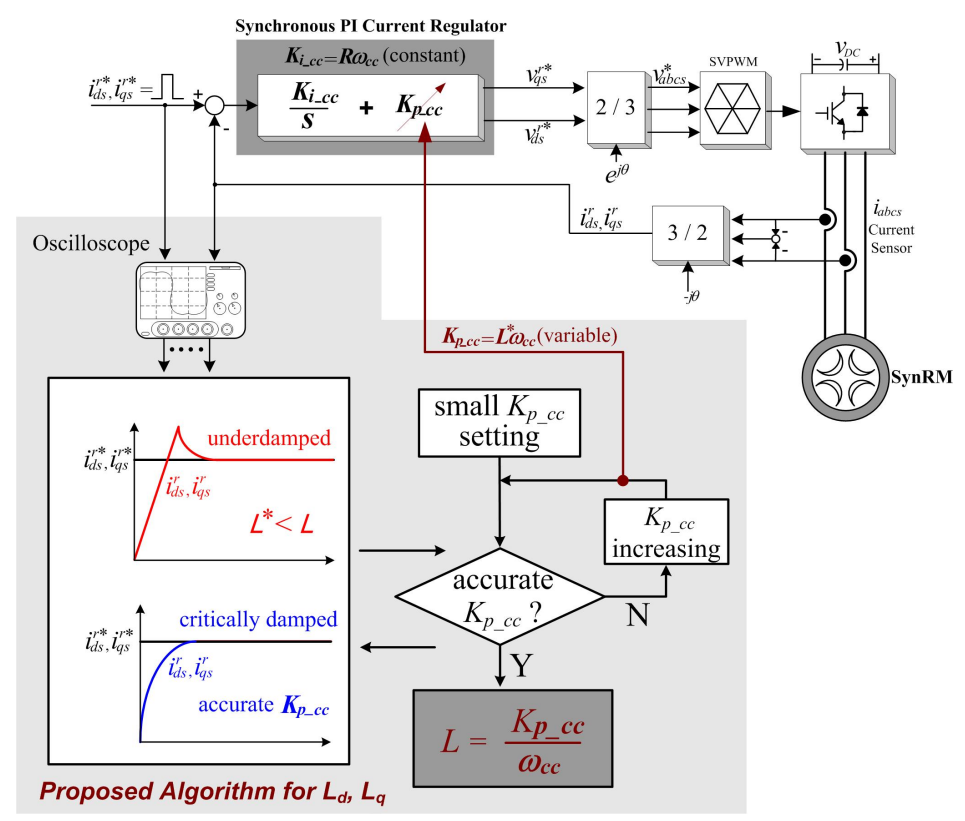

Fig. 4. Principle of inductance measurement at a current.

The real current is smaller than the reference current in (18), so the measured resistance is always larger than zero (19).

The $q$-axis resistance is also given by:

$$
R_{q}=\frac{i_{q}^{r^{*}}(t)}{i_{q}^{r}(t)} K_{p q_{-} c c}-K_{p q_{-} c c} .
$$

When the information about the real current, the reference current and the arbitrary proportional gain is known from the drive system, the real $d$ - and $q$-axis resistances can be easily calculated by using (19), and (20) as shown in Fig. 3.

\section{Measurement of the stator inductances}

The fact that the PI gains of the synchronous PI current regulator affect the current responses of the drive system was already proven in [6]. The gains can be calculated from the known resistances and inductances as mentioned above. If the PI gains are obtained by using the exact electrical parameters, the real current tracks the reference current quite well. This means that the control performance of the current regulator depends on the electrical parameters.

The system resistances that include the effects of the switching devices and the connecting wires are already known from the previous step, that is, $R_{d}=R_{d}^{*}$ and $R_{q}=R_{q}^{*}$. (14) can be rearranged to get a current transfer function as in (21).

$$
\frac{I_{d}^{r}(s)}{I_{d}^{r^{*}}(s)}=\frac{\omega_{c c}\left(R_{d}+s L_{q}^{*}\right)}{L_{d} s^{2}+\left(\omega_{c c} L_{d}^{*}+R_{d}\right) s+R_{d} \omega_{c c}} .
$$

When the step function of the reference current is applied to (21), the $d$-axis current can be derived as the equation of the transient state shown in (22).

$$
i_{d}^{r}(t)=i_{d}^{r^{*}}(t)+k_{1} e^{-\delta t} i_{d}^{r^{*}}(t)+k_{2} e^{-\gamma t} i_{d}^{r^{*}}(t)
$$

where:

$$
\begin{aligned}
& k_{1}=\frac{\omega_{c c}}{L_{d}} \frac{1}{(\gamma-\delta)}\left(L_{d}^{*}-\frac{R_{d}}{\delta}\right) \\
& k_{2}=\frac{\omega_{c c}}{L_{d}} \frac{1}{(\gamma-\delta)}\left(\frac{R_{d}}{\gamma}-L_{d}^{*}\right) \\
& \delta=\frac{\left(\omega_{c c} L_{d}^{*}+R_{d}\right)-\sqrt{\left(\omega_{c c} L_{d}^{*}+R_{d}\right)^{2}-4 L_{d} \omega_{c c} R_{d}}}{2 L_{d}} \\
& \gamma=\frac{\left(\omega_{c c} L_{d}^{*}+R_{d}\right)+\sqrt{\left(\omega_{c c} L_{d}^{*}+R_{d}\right)^{2}-4 L_{d} \omega_{c c} R_{d}}}{2 L_{d}}
\end{aligned}
$$

The current response of (22) is analyzed as follows: At $t=0$ :

$$
i_{d}^{r}(t)=i_{d}^{r^{*}}(t)+i_{d}^{r^{*}}(t) \frac{\omega_{c c}}{L_{d}} \frac{1}{(\gamma-\delta)}\left(\frac{R_{d}}{\gamma}-\frac{R_{d}}{\delta}\right)=0
$$

$\boldsymbol{A t} \boldsymbol{t}=\boldsymbol{t}_{1}$, just before the steady state, $e^{-\delta t}>>e^{-\gamma t}(\gamma>>$ $\delta$ ) is satisfied and the $d$-axis current is approximately obtained at $t_{1}$ as in (24):

$$
i_{d}^{r}(t) \approx r_{d}^{r^{*}}(t)+k_{1} e^{-\delta t} i_{d}^{r^{*}}(t)
$$

The current response in (24) can be divided into three cases:

- Case (1): if $L_{d}>L_{d}^{*}: k_{1}>0 ; i_{d}^{r}(t)>i_{d}^{r^{*}}(t)$ : underdamped.

- Case (2): if $L_{d}=L_{d}^{*}: k_{1}=0 ; i_{d}^{r}(t)=i_{d}^{r^{*}}(t)$ : critically damped.

- Case (3): if $L_{d}<L_{d}^{*}: k_{1}<0 ; i_{d}^{r}(t)<i_{d}^{r^{*}}(t)$ : underdamped.

$\boldsymbol{A t} \boldsymbol{t}=+\infty: \mathbf{e}^{-\delta t}=\mathbf{0}, \mathbf{e}^{-\gamma t}=\mathbf{0}: i_{d}^{r}(t)=i_{d}^{r^{*}}(t)$, the current reaches the steady state.

The analysis of the $q$-axis current response is the same as the $d$-axis current analysis that was just presented.

It is known from the analysis of (24), that the real current can track the reference well if and only if the known inductances are equal to the real inductances. Therefore, only case (2) can be used to determine the real inductances. 


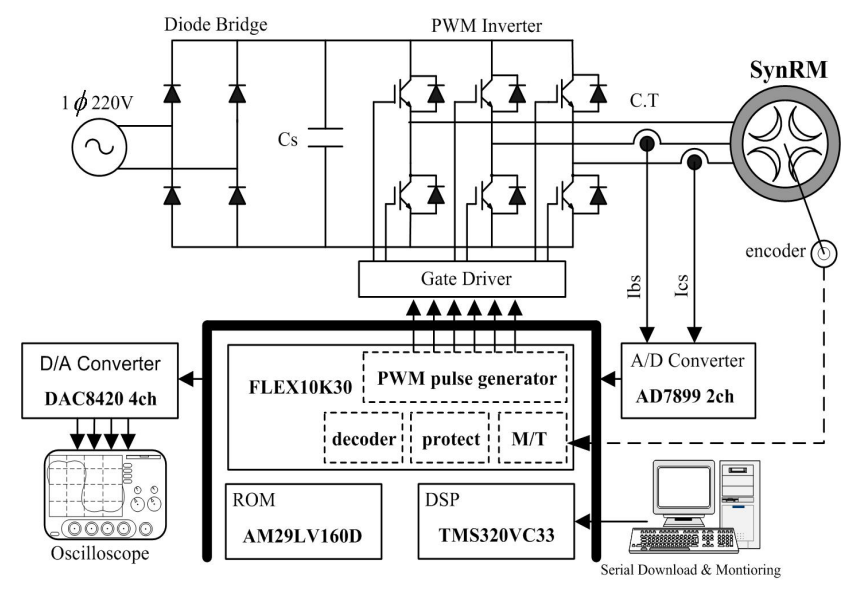

Fig. 5. Experimental drive system for SynRM.

The method of measuring the inductances is shown in Fig. 4 , and is based on the following three steps:

- First, the proportional gain is adjusted to a small enough value to produce an overshoot in the current response.

- Then, the proportional gain is increased step by step until the overshoot is eliminated. When there is no overshoot, the minimum proportional value is the accurate $\mathrm{P}$ gain.

- The real inductance equals the proportional gain divided by the bandwidth of the PI current regulator.

The same procedure is needed to measure the $q$-axis inductance. The resultant equations for the inductance values are given in (25) and (26), respectively.

$$
\begin{aligned}
& L_{d}=L_{d}^{*}=K_{p d_{-} c c} / \omega_{c c} \\
& L_{q}=L_{q}^{*}=K_{p q_{-} c c} / \omega_{c c} .
\end{aligned}
$$

\section{EXPERIMENTAl Results}

Fig. 5 shows the control system of the SynRM that was used to verify the proposed method experimentally. This system consists of a DSP board with a TMS320VC33 and FPGA, a diode bridge rectifier, an inverter using an IPM (Intelligent Power Module), and a 3 HP SynRM with 4-poles. The sampling period of the current regulator is $100 \mu \mathrm{s}$. The PWM switching frequency is $5 \mathrm{kHz}$.

\section{A. Using the VI method}

Two terminals of the SynRM were connected to the adjustable ac power supply as shown in Fig. 1. The phase resistance was determined by a prior dc test. The stator currents and voltages were measured by slowly rotating the rotor mechanically from 0 to $2 \pi$ in one direction, and the inductances can be calculated by using (5), (6), and (8).

Fig. 6 shows the experimental results of the measured inductances by changing the current range from 1 to $10 \mathrm{~A}$. In the real system, it is not easy to measure the exact electrical parameters of the SynRM by using the VI method due to the saturation effect of the stator inductance as shown in Fig. 6.

This effect adds an additional error to the stator inductance of the VI method.

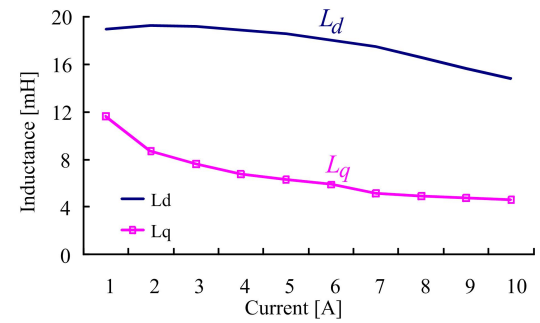

Fig. 6. Experimental results of inductance measurement using VI method.

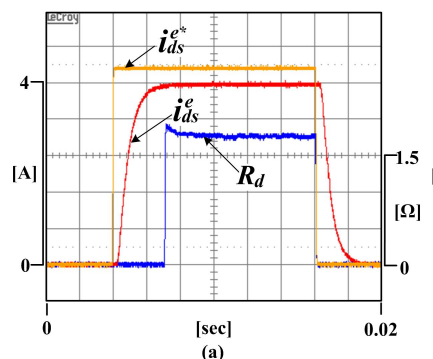

Fig. 7. Experimental results of $d q$-axis resistances.

\section{B. Proposed method}

1) Measurement of resistances: Fig. 7 shows the current responses of the $d$ - and $q$ - axis currents at $4 \mathrm{~A}$ and the calculated $d$ - and $q$-axis resistances in the steady state by using (19) and (20), respectively. The P gain is chosen arbitrarily only to observe the waveform of the current response and to measure the $d$ - and $q$-axis resistances including the effects of the inverter and the connecting wires.

The experimental results of the $d$ - and $q$-axis resistances and the dc resistance $R \_d c$ of the VI method are shown in Fig. 8. The current level is easily varied by using the reference current of inverter system from 0 to $10 \mathrm{~A}$ with the short duration of the one pulse current as shown in Fig. 7. The resistance steadily decreases when the test current increases. This phenomenon mainly comes from the nonlinear characteristics of the switching devices. A small deviation between the $d$ - and $q$ - axis resistances results from the Park transformation.

In order to determine the exact integral gains (I-gains) of the synchronous PI current regulator, the $d$ - and $q$-axis resistances must be used. Inaccurate integral gains can cause a deterioration of the system performance not only in the steady state but also in the transient state. The proposed method, that exactly measures the electrical parameters of the inverter fed SynRM including the effect of the switching devices and the connecting wires, guarantees improved drive performance of SynRMs.

2) Measurement of the stator inductances: Fig. 9 shows the waveforms of the $d q$-axis currents for three cases: underdamped, critically damped, and overdamped.

First, the proportional gain $\left(K_{p_{-} c c}\right)$ of the $d$-axis or the $q$ axis is set to a small value by using a small input inductance to produce an overshoot as shown in Figs. 9 (a) and (d), respectively. Then, $K_{p_{-} c c}$ is increased slowly to eliminate the overshoot.

Figs. 9 (b) and (e) show the critically damped current 


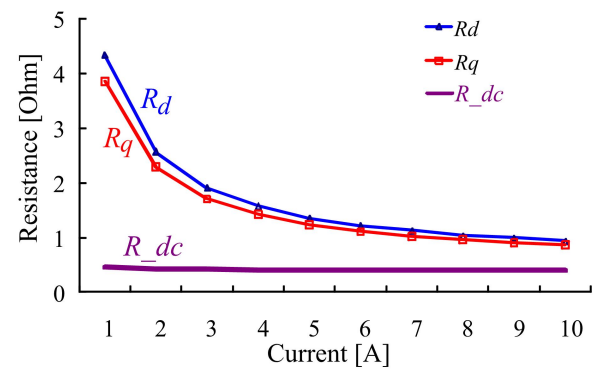

Fig. 8. Experimental results of $d q$-axis and dc resistances by using the proposed and dc method.

responses with suitable gains and accurate parameters. The synchronous inductances are calculated directly by using the accurate proportional gains and the bandwidth as shown in (25) and (26), respectively.

Fig. 10 shows a comparison of the experimental results of inductances between the VI method and the proposed method. The $q$-axis inductance approaches the saturated region earlier than the $d$-axis inductance because of the rotor structure in the SynRM. As shown in Fig. 10, the proposed method is implemented by using the short duration of the step current to measure the electrical parameters. In addition, the measurement errors between the VI method and the proposed algorithm below $3[\mathrm{~A}]$ are generated by measurement noises in the regions of the low reference currents.

A better system response was obtained from the well tuned parameters and PI gains not only in the steady state but also in the transient state as shown in Fig. 11. The inductance deviation between the two methods is small as shown in Fig. 10. If the parameters of the VI method are used, the large deviation of stator resistance seen in Fig. 8 causes an overdamped response as shown in Fig. 11. Therefore, the proposed method was used to exactly measure the electrical parameters of SynRMs as shown in Figs. 7, 8, 9, 10, and 11.

\section{Effect of motor parameters on system response}

To evaluate the feasibility of the proposed method, the inverter fed SynRM is tested from standstill to $500 \mathrm{r} / \mathrm{min}$ without a load. The PI gains calculated from the parameters of the VI and proposed methods were turned to adapt to the operating currents. The experimental waveforms of the $d$-and $q$-axis currents are shown in Fig. 11 (a), (b), (c), and (d), (e), (f), respectively.

\section{CONCLUSIONS}

This paper proposes a new algorithm to measure the electrical parameters of a SynRM by using a synchronous PI current regulator at a standstill. The proposed algorithm can be easily and safely implemented by simultaneously using the short one-pulse and closed equations of resistance and synchronous inductances. Furthermore, the measurement time can be greatly reduced. In addition, the drive system itself is capable of measuring the electrical parameters, taking into full consideration the effects of the switching devices, connecting wires, and saturation by using the proposed method. It does not need any external or additional equipment for the

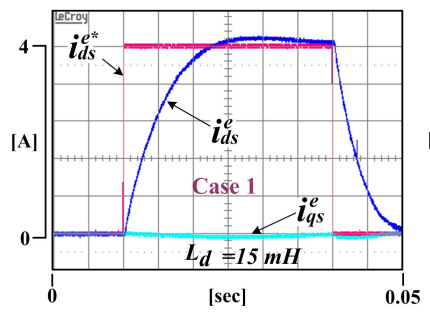

(a)

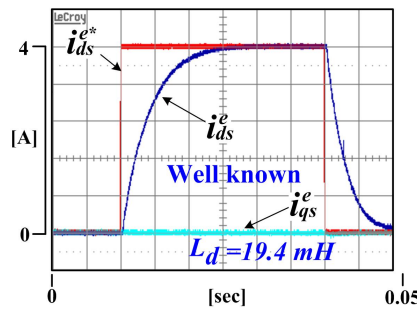

(b)

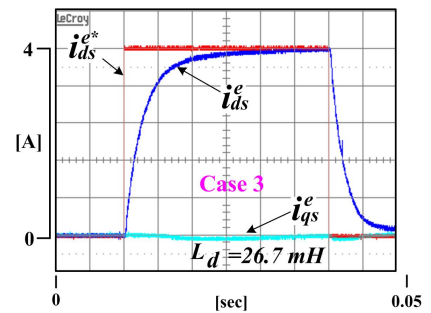

(c)

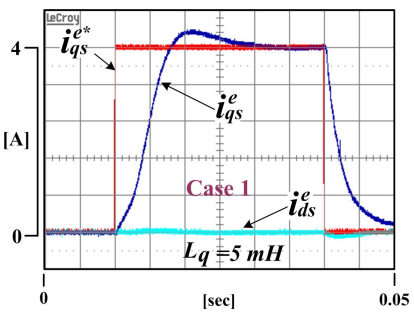

(d)

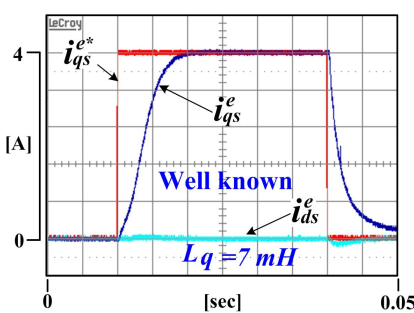

(e)

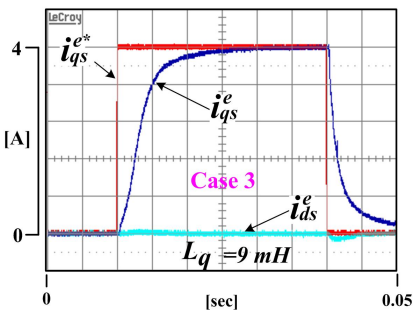

(f)
Fig. 9. Experimental results of $d q$-axis inductances measurement by using the proposed algorithm. (a) $d$-axis current underdamped. (b) $d$-axis current critically damped. (c) $d$-axis current overdamped. (d) $q$-axis current underdamped. (e) $q$-axis current critically damped. (f) $q$-axis current overdamped.

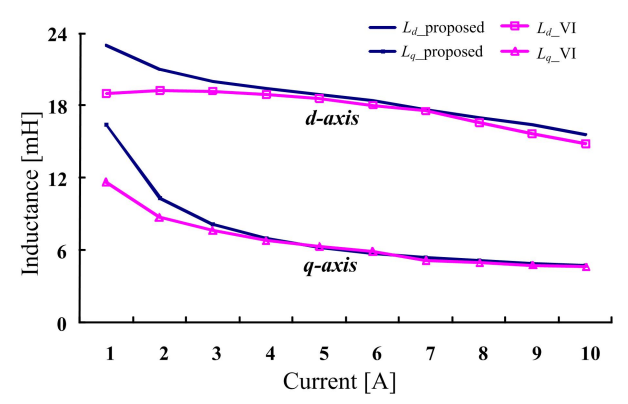

Fig. 10. Comparison results of synchronous $d q$-axis inductances between VI method and proposed method.

measurement. Moreover, this method can measure the exact electrical parameters without any information on the motor's dimension or material characteristics as in the case of FEM. The effectiveness of the proposed algorithm is verified through several experimental results.

\section{ACKNOWLEDGMENT}

This work was supported by the Energy Efficiency \& Resources of the Korea Institute of Energy Technology Evaluation and Planning (KETEP) grant funded by the Korea Government Ministry of Knowledge Economy (No. 2008-PEO-HM-E-01-0000). 

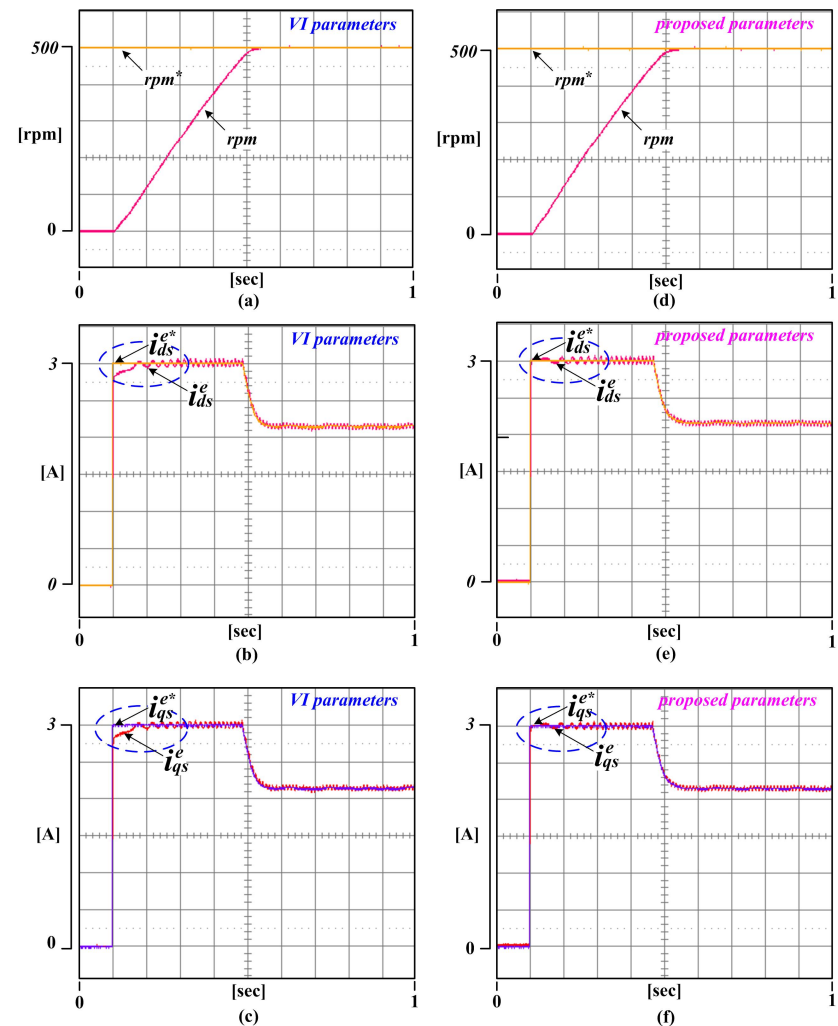

Fig. 11. Experimental results of speed and $d q$-axes current responses. (a), (b), and (c) VI method. (d), (e), and (f) proposed algorithm.

\section{REFERENCES}

[1] Jovanovic, M.G., Betz, R.E., and Jian Yu, "The use of doubly fed reluctance machines for large pumps and wind turbines," IEEE Trans. Ind. Applicat., Vol. 38, No. 6, Nov./Dec. 2002.

[2] Vagati, A., Pastorelli, M., and Franceschini, G, "High-performance control of synchronous reluctance motors," IEEE Trans. Ind. Applicat., Vol. 33, No. 4, Jul./Aug. 1997.

[3] Seog-Joo Kang, Jang-Mok Kim, and Seung- Ki Sul, "Position sensorless control of synchronous reluctance motor using high frequency current injection," IEEE Trans. Energy Conversion, Vol. 14. No. 4, Dec. 1999.

[4] Chalmers, B.J. and Musaba, L., "Design and field-weakening performance of a synchronous reluctance motor with axially laminated rotor," IEEE Trans. Ind. Applicat., Vol. 34, No. 5, Sep./Oct., 1998.

[5] R.E.betz, R.Lagerquist, and M. Jovanovic, T. J. E Miller, R. Middleton, "Control of synchronous reluctance motor," IEEE Trans. Ind. Applicat., Vol. 29, No. 6, Nov./Dec. 1993.

[6] Fernando Briz, Michael W. Degner, and Robert D. Lorenz "Analysis and design of current regulators using complex vectors," IEEE Trans. Ind. Applicat., Vol. 36, May/Jun. 2000.

[7] Lubin, T., Razik, H., and Rezzoug, A., "Magnetic saturation effects on the control of a synchronous reluctance machine," IEEE Trans. Energy Conversion, Vol. 17, No. 3, Sep. 2002.

[8] Wung, P.Y.P. and Puttgen, H.B, "Synchronous reluctance motor operating point dependent parameter determination," IEEE Trans. Ind. Applicat., Vol. 28, No. 2, Mar./Apr. 1992

[9] Ping Zheng, Thelin, P., Anyuan Chen, and Nordlund, E., "Influence of saturation and saliency on the inductance of a four-quadrant transducer prototype machine," IEEE Trans. Magn., Vol. 42, No. 4, Apr. 2006.

[10] Wen-Nan Huang, Ching-Cheng Teng, Chih-Hsing Fang, and ChihHsin Chen, "Inductance measurement and estimation method utilizing LC circuit analysis techniques under dynamic operation for switched reluctance (SR) machines," Industrial Electronics Society, 30th Annual Conference of IEEE, Vol. 3, 2004

[11] Nikolay Radimov, Natan Ben-Hail, and Raul Rabinovici, "Inductance measurements in Switched reluctance machines," IEEE Trans. Magn., Vol. 41. No. 4, Apr. 2005.
[12] Senjyu, T., Omoda, A., and Uezato, K., "Parameter measurement for synchronous reluctance motors considering stator and rotor iron loss," Electric Machines and Drives, International Conference IEMD '99, May 1999.

[13] A. A. Arkadan, F. N. Isaac, and O. A. Mohammed, "Parameters evaluation of ALA synchronous reluctance motor drives," IEEE Trans. Magn., Vol. 36, No. 4, Jul. 2000.

[14] Kilthau. A and Pacas, J, "Parameter measurement and control of the synchronous reluctance machine including cross saturation," IEEE IAS Annual meeting, 2001

[15] Shinji Ichikawa, Mutuwo Tomita, Shinji Doki, and Shigeru Okuma, "Sensorless control of synchrnous reluctance motors based on extended EMF models considering megnetic saturation with online parameter identification," IEEE Trans. Ind. Applicat., Vol. 42. No. 5 Sep./Oct. 2006.

[16] Kazuhiro Ohyama and Katsuji Shinohara, "Small-signal stability analysis of vector control system of induction motor without speed sensor using synchronous current regulator," IEEE Trans. Ind. Applicat., Vol. 36, No. 6, Nov./Dec. 2000.

[17] Hyunbae Kim and Lorenz, R.D, "Improved current regulators for IPM machine drives using on-line parameter estimation," IEEE IAS Annual Meeting, Vol. 1, 2002.

[18] Paul C. Kreause, Oleg Wasynczuk, and Scott D. Sudhoff, Analysis of Electric Machinery, IEEE Press, pp. 135 145, 1994.

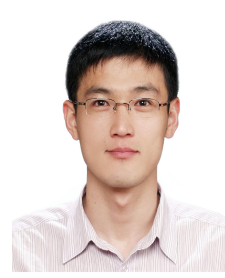

Seon-Hwan Hwang was born in Chungnam, Korea, in 1978. He received his B.S. and M.S. in Electrical Engineering from Pusan National University, Busan, Korea, in 2004 and 2006, respectively. He is currently working toward his Ph.D. at Pusan National University. His research interests include power conversion and electric machine drives.

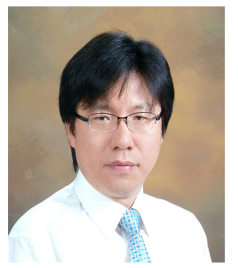

Jang-Mok Kim was born in Busan, Korea, in August 1961. He received his B.S. from Pusan National University in 1988, and his M.S. and Ph.D. from Seoul National University, Korea, in 1991 and 1996, respectively, in the Department of Electrical Engineering. From 1997 to 2000, he was a Senior Research Engineer with the Korea Electrical Power Research Institute (KEPRI) Since 2001, he has been with the School of Electrical Engineering, Pusan National University (PNU), where he is currently a faculty member. In addition, he is a Research Member of the Research Institute of Computer Information and Communication at PNU. His present interests include the control of electric machines, electric vehicle propulsion, and power quality.

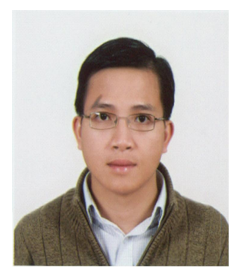

Huynh Van Khang was born in Binh Dinh, Vietnam, in 1979. He received his B.S. from the Ho Chi Minh City University of Technology, Vietnam in 2002, and his M.S. from Pusan National University, Korea in 2008. Currently, he is a researcher in the Electromechanics group, Aalto University, Finland where he is working toward his Ph.D. His research interests include electrical machines and drives.

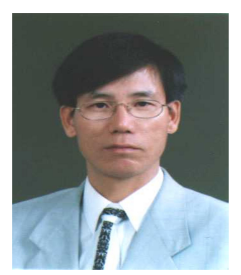

Jin-Woo Ahn was born in Busan, Korea, in 1958. He received his B.S., M.S., and Ph.D. in Electrical Engineering from Pusan National University, Busan, Korea, in 1984, 1986, and 1992, respectively. He has been with Kyungsung University, Busan, Korea, as a Professor in the Department of Electrical and Mechatronics Engineering since 1992. He was a Visiting Professor in the Department of Electrical Engineering, UW-Madison, USA. He is the author of five books including SRM and the author of more than 100 papers. His current research interests are motor drive systems and electric vehicle drives. Dr. Ahn was listed in "Who's Who in the World 2003" (The Marquis Who's Who Publications Board, USA) and also in "Leading Scientists of the World 2006" (International Biographical Centre, UK). He is a Senior Member of IEEE, a Senior Member of Korean Institute of Electrical Engineers and a Member of the Korean Institute of Power Electronics. 